\title{
A robust high-speed sliding mode control of permanent magnet synchronous motor based on simplified hysteresis current comparison
}

\author{
Ifeanyi Chinaeke-Ogbuka ${ }^{1}$, Augustine Ajibo ${ }^{2}$, Kenneth Odo $^{3}$, Uche Ogbuefi ${ }^{4}$, Muncho Mbunwe ${ }^{5}$, \\ Cosmas Ogbuka ${ }^{6}$, Emenike Ejiogu $^{7}$ \\ ${ }^{1,2}$ Department of Electronic Engineering, University of Nigeria, Nsukka, Nigeria \\ 3,4,5,6,7 Department of Electrical Engineering, University of Nigeria, Nsukka, Nigeria \\ 3,4,5,6,7 Africa Centre of Excellence for Sustinalbe Power and Energy Development, ACE-SPED, \\ University of Nigeria, Nsukka, Nigeria \\ ${ }^{6,7}$ Laboratory of Industrial Electronics, Power Devices and New Energy Systems, University of Nigeria, Nsukka, Nigeria
}

\begin{tabular}{|c|c|}
\hline Article Info & ABSTRACT \\
\hline Article history: & \multirow{13}{*}{$\begin{array}{l}\text { A robust high-speed sliding mode control (SMC) of three phase permanent } \\
\text { magnet synchronous motor (PMSM) is presented. The SMC served for inner } \\
\text { speed control while a simplified hysteresis current control (HCC) scheme } \\
\text { was used in the outer current control to generate gating signals for the } \\
\text { inverter switches. The present research leverages on the ability of SMC to } \\
\text { directly access system speed error which it attempts driving to zero by } \\
\text { cancelling modelling uncertainties and disturbances. Performance } \\
\text { comparison was done for the SMC model and an existing model having } \\
\text { classical PI controller. With the initial positive speed command of } 200 \mathrm{rpm} \text { at } \\
5 \mathrm{Nm} \text { constant loading, rotor speed with SMC neatly settled to the reference } \\
\text { speed at } 0.085 \text { seconds without overshoot while the rotor speed of the model } \\
\text { with PI controller settled at } 0.217 \text { seconds after overshoot. This translates to } \\
155.3 \% \text { speed enhancement. Similar superior speed performance of the SMC } \\
\text { was also observed during recovering from sudden speed reversal. While the } \\
\text { SMC model recovered and settled to the reference speed of -200 rpm at } \\
0.369 \text { seconds, the model with PI controller settled at } 0.482 \text { seconds. From } \\
\text { the results, it can be seen that SMC demonstared superiority over the } \\
\text { conventioanl PI controller for complex drives systems. }\end{array}$} \\
\hline Received Sep 19, 2020 & \\
\hline Revised Jan 19, 2021 & \\
\hline Accepted Feb 4, 2021 & \\
\hline & \\
\hline Keywords: & \\
\hline Hysteresis current control & \\
\hline PI controller & \\
\hline PMSM & \\
\hline Sliding mode control & \\
\hline & \\
\hline Voltage source inverter & \\
\hline & \\
\hline
\end{tabular}

This is an open access article under the CC BY-SA license.

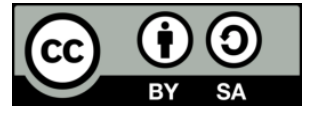

\section{Corresponding Author:}

Cosmas Ogbuka

Dept. of Electrical Engineering/Africa Centre of Excellence for Sustainable Power and Energy

Development (ACE-SPED), University of Nigeria, Nsukka, Nigeria

Email: cosmas.ogbuka@unn.edu.ng

\section{INTRODUCTION}

The popularity of controlled permanent magnet synchronous motors (PMSMs) is on the increase for applications in the industry within the medium and low power ranges. They have superior characteristics such as high torque/inertia ratio, compact size, lower noise and accurate positioning [1]-[5]. PMSMs have the advantage of high efficiency when compared with the induction motor [6], high reliability, fast dynamics and very good compatibility [7]-[8]. The absence of rotor winding due to the use of the rotor magnets is responsible for the enhanced features. Complexity of PMSM makes it a nonlinear system coupled with its exposure to uncertainties such as perturbations, disturbances and load changes [9]-[14]. 
Several non-linear control methods have been used in the torque and speed control of PMSMs. A fuzzy adaptive internal model control (IMC) schemes, considering control input saturation, was presented in [15]. The backstepping speed observer and adaptive backstepping control were used in [16] for PMSM speed and torque control via current source inverter (CSI). The scheme showed robustness on both electromagnetic and mechanical parameters of the motor. Linear quadratic regulator (LQR) utilizing quadratic cost function for the determination of control performance was used in [17] to linearize the inherently non-linear mathematical model of the motor. Results from this control technique show that LQR exhibits better system dynamic performance with reference to transition time and speed overshoot in comparison with traditional PID controller.

Other nonlinear methods that have been used to control the PMSM includes a neural network loss minimization control [18], generalized predictive control (GPC), sliding mode controller (SMC) [19]-[20], fuzzy logic controller (FLC) [21]. Generally, when compared to the linear control using PID controllers, nonlinear control methods, since the PMSMs are complex nonlinear systems, are more suitable in achieving better systems dynamics and steady state performance. In this work, sliding mode control (SMC) is employed for accurate speed and position sensing for PMSM drive that employs a robust HCC for inverter gating signal generation. Specifically, the present research leverages on the unique ability of the SMC to have direct access to the systems speed error which it attempts driving to zero by cancelling modelling uncertainties and disturbances. Results obtained were compared with results obtained in the model of [3], [12] where the same simplified HCC was used for outer current control but classical PI speed controller was employed for inner speed loop control of the same drives system. MATLAB/Simulink 2018 version was used for modelling and simulation in this research.

\section{D-Q MODELLING OF PMSM}

The rotor permanent magnets are responsible for the production of the main magnetic flux. Thus, dq-axis voltage equations, the electromagnetic torque and the system mechanical models are respectively derived as [3], [22]-[23]:

$$
\begin{aligned}
& {\left[\begin{array}{l}
V_{q} \\
V_{d}
\end{array}\right]=\left[\begin{array}{cc}
R_{s}+\frac{d L_{q}}{d t} & \omega_{r} L_{d} \\
-\omega_{r} L_{q} & R_{s}+\frac{d L_{d}}{d t}
\end{array}\right]\left[\begin{array}{l}
i_{q} \\
i_{d}
\end{array}\right]+\left[\begin{array}{c}
\omega_{r} \varphi_{m} \\
\frac{d \varphi_{m}}{d t}
\end{array}\right]} \\
& T_{e}=\frac{3}{2} \frac{P}{2}\left[\varphi_{m} i_{q}+\left(L_{d}-L_{q}\right) i_{d} i_{q}\right] \\
& T_{e}=T_{L}+B \omega_{r}+\frac{J d \omega_{r}}{d t}
\end{aligned}
$$

where, $V_{d}, V_{q}, i_{d}, i_{q}, \omega_{r}, R_{s}, L_{d}, L_{q}, B, J, T_{L}, T_{e}$ and $P$ are as defined in [7]. The constant rotor permanent magnet flux is $\varphi_{m}$, hence $\frac{d \varphi_{m}}{d t}=0$.

\section{SMC SPEED CONTROL OF PMSM}

Speed error $e$ is the difference between the commanded speed reference, $\omega_{d}$, and the rotor speed feedback, $\omega_{r}$, such that $e=\omega_{d}-\omega_{r}$ [24], [25]. From (3),

$$
\frac{d \omega_{r}}{d t}=\frac{T_{e}}{J}-\frac{T_{L}}{J}-\frac{B \omega_{r}}{J}
$$

from (2), for a surface PMSM,

$$
\begin{aligned}
& \frac{d \omega_{r}}{d t}=\frac{3 P \varphi_{m} i_{q}}{2 J}-\frac{T_{L}}{J}-\frac{B \omega_{r}}{J} \\
& \dot{\omega}_{r}=\frac{3 P \varphi_{m} i_{q}}{2 J}-\frac{T_{L}}{J}-\frac{B \omega_{r}}{J}
\end{aligned}
$$

taking the derivative of the tracking error $(e)$, we have (6): 


$$
\begin{aligned}
& \dot{e}=\dot{\omega}_{d}-\dot{\omega}_{r} \\
& \dot{e}=\dot{\omega}_{d}-\left[\frac{3 P \varphi_{m} i_{q}}{2 J}-\frac{T_{L}}{J}-\frac{B \omega_{r}}{J}\right]
\end{aligned}
$$

taking double derivative of $e$ we have (7):

$$
\begin{aligned}
& \ddot{e}=\ddot{\omega}_{d}-\ddot{\omega}_{r} \\
& \ddot{e}=\ddot{\omega}_{d}-\frac{d}{d t} \dot{\omega}_{r} \\
& \ddot{e}=\ddot{\omega}_{d}-\frac{d}{d t}\left[\frac{3 P \varphi_{m} i_{q}}{2 J}-\frac{T_{L}}{J}-\frac{B \omega_{r}}{J}\right] \\
& \ddot{e}=\ddot{\omega}_{d}-\left[\frac{3 P \varphi_{m} \dot{i}_{q}}{2 J}-0-\frac{B \dot{\omega}_{r}}{J}\right] \\
& \ddot{e}=\ddot{\omega}_{d}-\left[\frac{3 P \varphi_{m} i_{q}}{2 J}-\frac{B \dot{\omega}_{r}}{J}\right]
\end{aligned}
$$

defining the sliding surface, we have (8):

$$
s=\dot{e}+c e
$$

The PMSM speed system equivalent controller is calculated by setting $\dot{s}=0$

$$
\begin{aligned}
& \dot{s}=\ddot{e}+c \dot{e} \\
& \dot{s}=\left[\ddot{w}_{d}-\frac{3 P \varphi_{m} i_{q}}{2 J}+\frac{B \dot{\omega}_{r}}{J}\right]+c \dot{e}=0
\end{aligned}
$$

therefore from:

$$
\begin{aligned}
& \ddot{\omega}_{d}-\frac{3 P \varphi_{m} \dot{i}_{q}}{2 J}+\frac{B \dot{\omega}_{r}}{J}+c \dot{e}=0 \\
& \frac{3 P \varphi_{m} l_{q}}{2 J}=\ddot{\omega}_{d}+\frac{B \dot{\omega}_{r}}{J}+c \dot{e}
\end{aligned}
$$

setting $\frac{3 P \varphi_{m}}{2 J}=b$

$$
\begin{aligned}
& \therefore b \dot{i_{q}}=\ddot{\omega}_{d}+\frac{B \dot{\omega}_{r}}{J}+c \dot{e} \\
& \dot{i_{q}}=\frac{1}{b}\left[\ddot{\omega}_{d}+\frac{B \dot{\omega}_{r}}{J}+c \dot{e}\right]
\end{aligned}
$$

integrating (12),

$$
i_{q}=\frac{1}{b}\left[\dot{\omega}_{d}+\frac{B \omega_{r}}{J}+c e\right]
$$

the equivalent control $U_{e q}=i_{q}[26]$

$$
\therefore u_{e q}=\frac{1}{b}\left[\dot{\omega}_{d}+\frac{B \omega_{r}}{J}+c e\right]
$$

the switching controller is designed as (14):

$$
u_{s}=k \operatorname{sgn}(s)
$$

the parameter $k>0$ is a controller gain

finally, the control law is a sum of of (13) and (14):

$$
U=u_{e q}+u_{s}=\frac{1}{b}\left[\dot{\omega}_{d}+\frac{B \omega_{r}}{J}+c e\right]+k \operatorname{sgn}(s)
$$

Figure 1 is a block diagram of (1) 


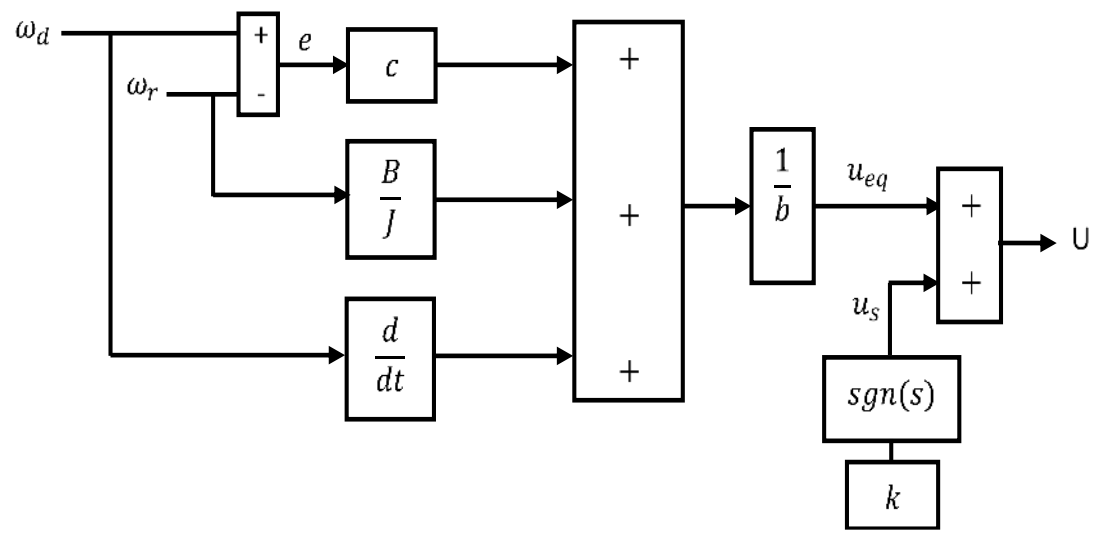

Figure 1. SMC controller block diagram

\section{OVERALL CONTROL PROCEDURE}

Complete system diagram is shown in Figure 2. Rotor sensed speed $\omega_{r}$ is processed by a 1st order low pass filter before comparison with reference speed $\omega_{d}$. An error $e=\omega_{d}-\omega_{r}$ is generated which, in addition to $\omega_{d}$ and $\omega_{r}$, serves as the input to the sliding mode control unit already described in Figure 1 . The SMC unit generates a suitable control signal $u$, which in this case, is stator q-axis reference current $\left(i_{q}^{*}\right)$. This drives the error, $e$, to zero by enabling the system speed response $\omega_{r}$ to attain the set reference $\omega_{d}$. The $i_{q}^{*}, i_{d}^{*}$ and $\theta_{e}$ are the input signals of the reference stator current estimator by inverse park's transform. The phase currents, $i_{a}, i_{b}$ and $i_{c}$, in conjunction with corresponding generated reference currents $i_{a}^{*}, i_{b}^{*}, i_{c}^{*}$ and $\Delta i_{q}^{*}$ are compared to generate the gating signals, as illustrated in Figure 3, for the inverter with power circuit shown in Figure 4. Where $\Delta$ is a variable hysteresis window. The control logic for the gating signal generation is illustrated in [22].

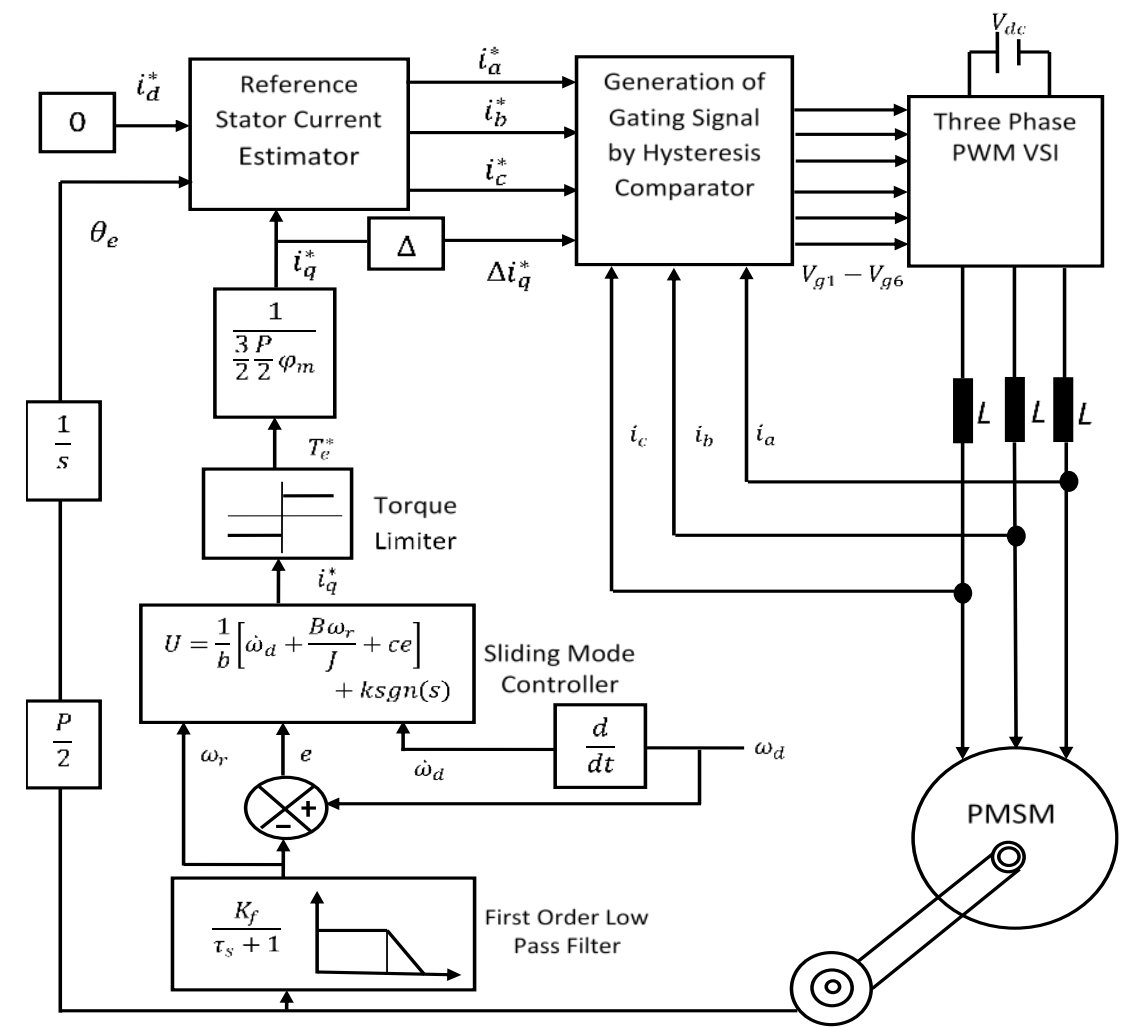

Figure 2. Complete system diagram of the PMSM drives with SMC 


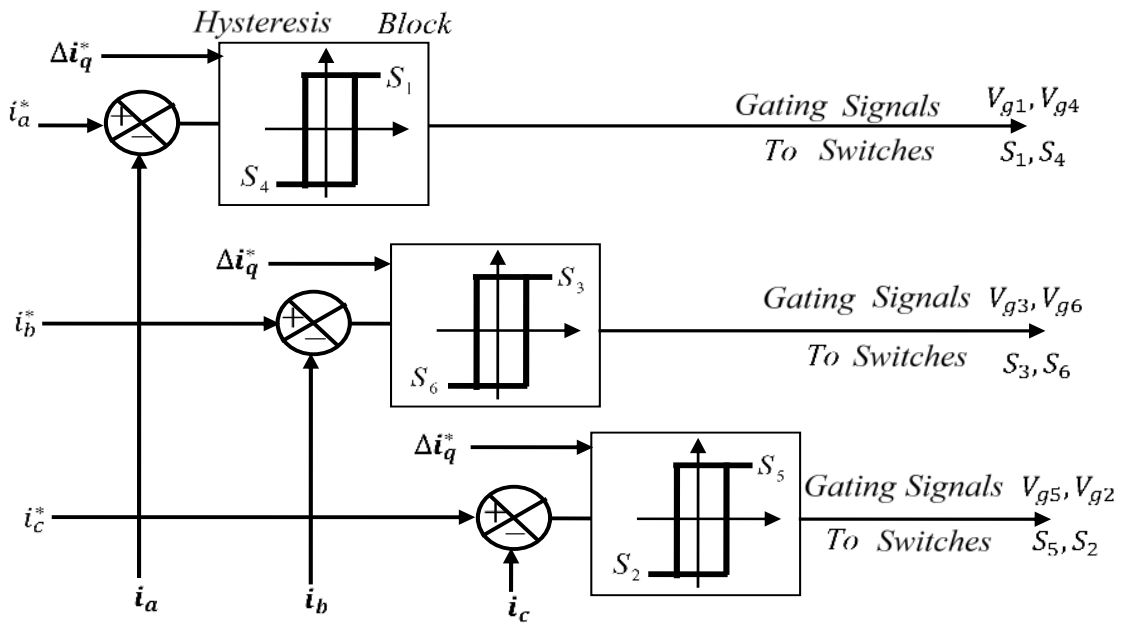

Figure 3. Generation of gating signals

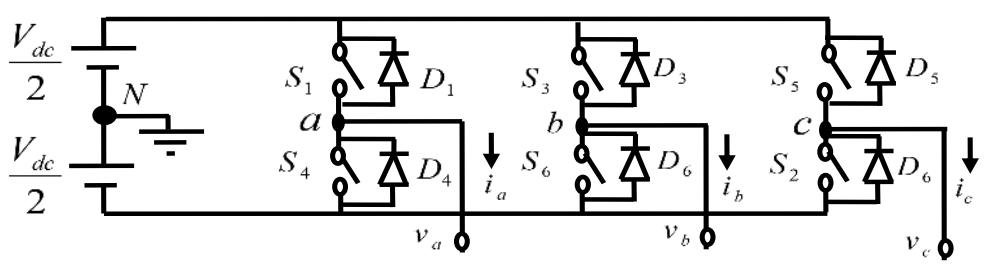

Figure 4: Three-phase inverter power circuit

\section{COMPARISON OF THE RESULTS}

In this section, plots of Figures 5-12 obtained from MATLAB/Simulink are used to compare the performance of this developed drives system employing SMC for inner speed control with the performance of the same system that employs classical PI controller for inner speed control as already reported in [3], [15]. In both cases, the outer current control is by HCC. PMSM parameters are shown in Table 1.

Table 1. PMSM parameters

\begin{tabular}{cc}
\hline Motor parameters & Value \\
\hline Rated Power & $4 \mathrm{Hp}$ \\
Frequency & $50 \mathrm{~Hz}$ \\
Stator resistance $(\mathrm{Rs})$ & $0.2 \Omega$ \\
Constamt rotor flux & $0.175 \mathrm{~Wb}$ \\
linkage $\left(\lambda_{f}\right)$ & \\
Inductance d axis $\left(L_{d}\right)$ & $0.0085 \mathrm{H}$ \\
Inductance q axis $\left(L_{q}\right)$ & $0.0085 \mathrm{H}$ \\
Inertia constant $(\mathrm{J})$ & $0.42 \mathrm{Kgm}^{2}$ \\
No. of poles $(\mathrm{P})$ & 6 \\
\hline
\end{tabular}

The sensed rotor speed obtained with SMC and the PI controllers are compared with the speed reference as shown in Figure 5. With a positive speed command of $200 \mathrm{rpm}$, speed response with the SMC neatly settled at the reference at 0.085 seconds without overshoot while the speed response of the PI controller experienced overshoot before settling to the speed refence at 0.217 seconds. Sudden (step) reference speed reversal from $200 \mathrm{rpm}$ to $-200 \mathrm{rpm}$ occurred at 0.25 seconds leading to change in speed orientation for the two models. At -200rpm, the SMC seamlessly traced the speed reference while the PI controller had negative overshot before settling to $-200 \mathrm{rpm}$. 


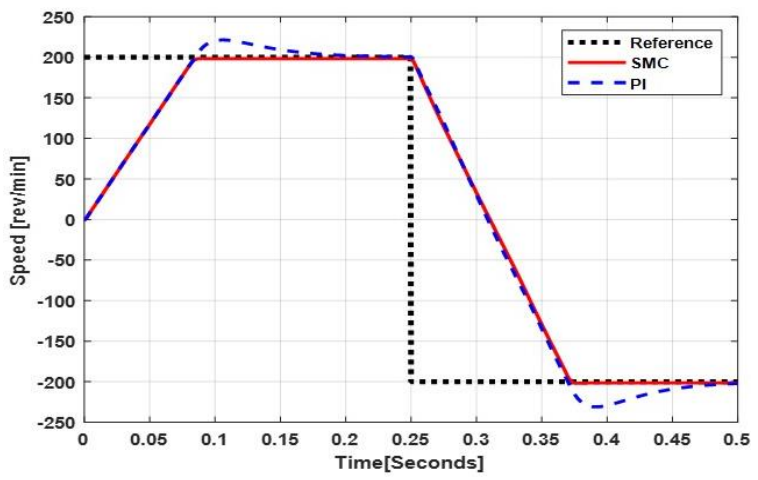

Figure 5. Reference speed, $\omega_{d}$ and rotor speed, $\omega_{r}$

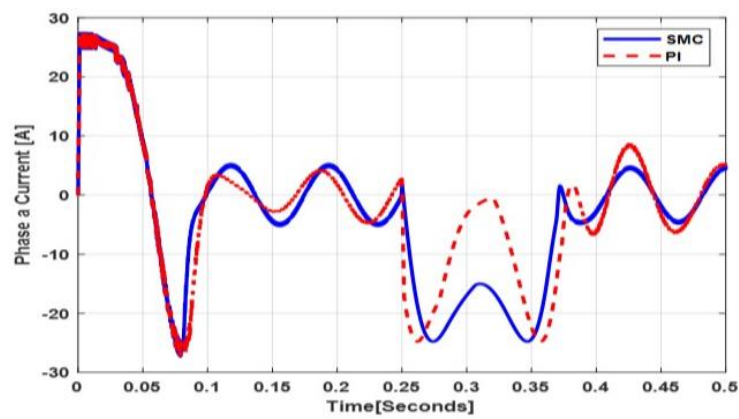

Figure 7. Stator current for Phase 'a'

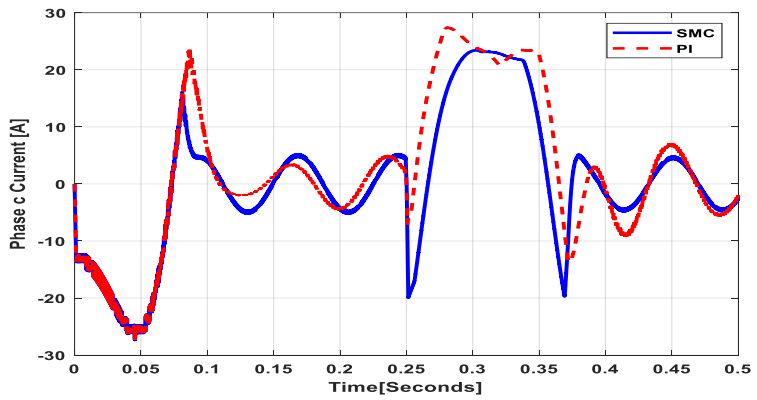

Figure 9. Stator current for phase 'c'

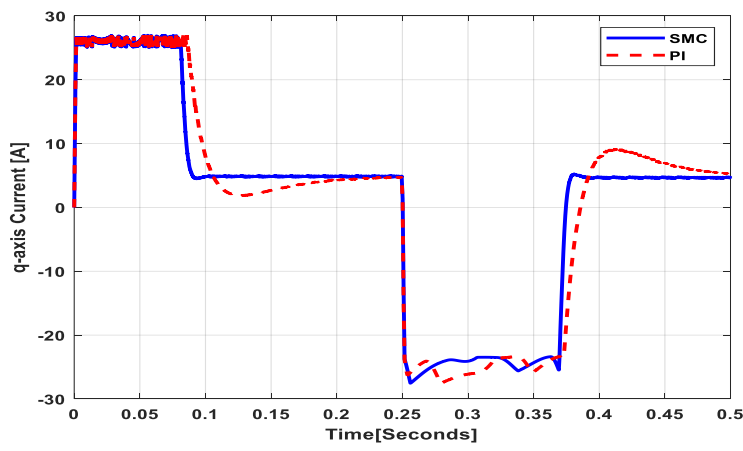

Figure 11. q axis stator current, $i_{q}$

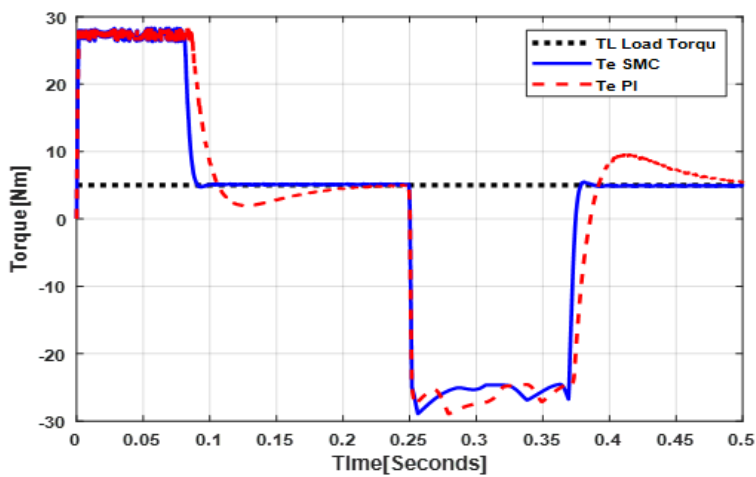

Figure 6. Electromagnetic torque, $T_{e}$ and load torque, $T_{L}$

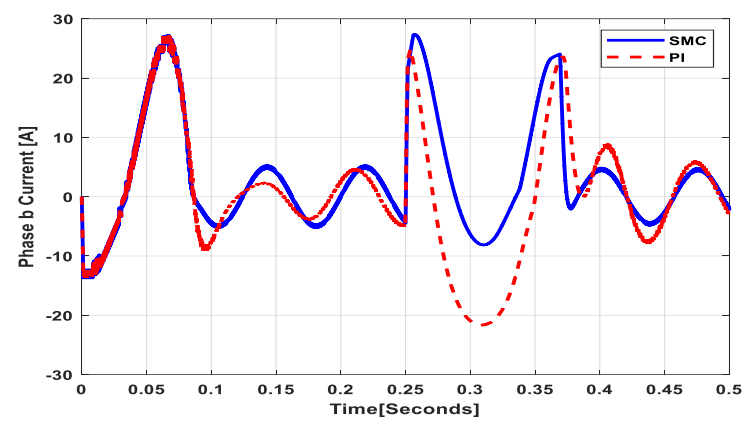

Figure 8. Stator current for Phase ' $b$ '

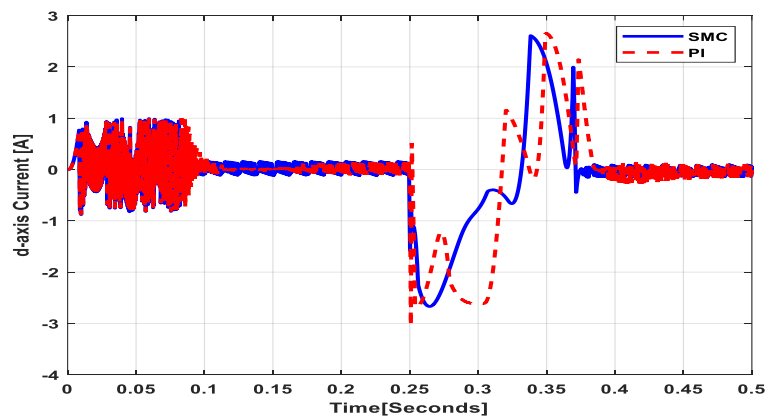

Figure 10. d axis stator current, $i_{d}$

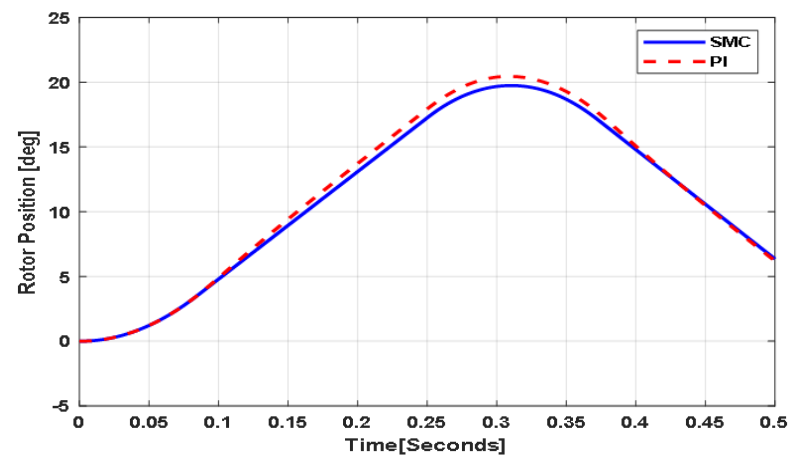

Figure 12. Rotor position, $\theta_{r}$ 
Figure 6 shows the load torque $T_{L}$ in comparison with the electromagnetic torque $T_{e}$ using the SMC and PI controller. The electromagnetic torque remained constant to sustain speed build-up. At the point when rotor speed equals reference speed, electromagnetic torque reduces to the load torque value of $5 \mathrm{Nm}$ with the model with SMC settling at the load torque faster since there is no speed overshot. Torque recovery due to speed reversal takes the same form with the model with SMC showing better dynamic behavior as shown.

The three phase currents for the model with SMC and PI are respectively compared for phases a, b, and $\mathrm{c}$ in Figures 7,8 and 9. Better dynamic performances are obtained for the model with SMC in each case. The models being field orientation controlled (FOC), the stator d-axis currents, shown in Figure 10, for the SMC and the PI models averages to zero to track the reference value which is zero in FOC. Current transients due to speed reversal are also seen.

The stator q-axis current, shown in Figure 11, is in direct proportion to electromagnetic torque $T_{e}$ because being the torque controlling component of the stator current. Faster dynamic behaviour was observed for SMC model. The rotor position for the two models is compared in Figure 12. Since the model with SMC attained steady state much faster than the model with PI controller, it is observed that the rotor position for the SMC, is at every time instant, ahead of the rotor position for the PI controller.

\section{CONCLUSION}

This research has leveraged on the unique ability of the SMC to have direct access to the systems speed error which it attempts driving to zero thereby cancelling modelling uncertainties and disturbances. SMC was employed for inner speed control of the motor while a simplified HCC was used for the outer current control. This is so because of the proportionality of torque and current in both stationery and rotor frames of reference whereby effective current control results in effective torque and speed control.

Responses from the developed SMC model were compared with responses from an earlier model that utilizes classical PI controller for inner speed control employed on the same PMSM under the same condition of step speed command from 200rpm to -200rpm and constant load torque of $5 \mathrm{Nm}$.

With the initial positive speed command of 200rpm at 5Nm loading, speed response with the SMC neatly settled at the reference at 0.085 seconds without overshoot while the speed response of the PI controller experienced overshoot before settling to the speed refence at 0.217 seconds. This translates to $155.3 \%$ speed enhancement. The same superior speed performance of the SMC is observed during recovering from sudden speed reversal at 0.25 seconds.

This research has provided sufficient evidence that the SMC exhibits more robust performance and faster response time than the PI controller in the control of complex drives systems under the same condition. MATLAB/Simulink 2018 version played a vital role in this research by presenting a suitable environment for modeling and simulation.

\section{ACKNOWLEDGEMENTS}

The Africa Centre of Excellence for Sustainable Power and Energy Development (ACE-SPED), University of Nigeria, Nsukka is acknowledged for the support that enabled the timely completion of this research.

\section{REFERENCES}

[1] Y. W. Hu, et al., "Direct torque control system and sensorless technique of permanent magnet synchronous motor," Chinese Journal of Aeronautics, vol.16, no. 2, pp. 97-102, 2003.

[2] C. Ogbuka, et al., "Dynamic and steady state performance comparison of line start permanent magnet synchronous motors with interior and surface rotor magnets," Archives of Electrical Engineering, vol. 65, no. 1, pp. 105-116, 2016.

[3] C. Ogbuka, et al., "A fast hysteresis current controlled permanent magnet synchronous motor drive based on field orientation," Journal of Electrical Engineering. vol. 67, no. 2, pp. 69-77, 2016.

[4] F. Tahami et al., "Maximum Torque per ampere control of permanent magnet synchronous motor using genetic algorithm," TELKOMNIKA Telecommunication, Computing, Electronics and Control, vol. 9, no. 2, pp. 237-244, 2011.

[5] A.S. Saari and D. Ishak, "Design and fault tolerant analysis of five-phase permanent magnet synchronous motor," Indonesian Journal of Electrical Engineering and Computer Science (IJEECS), vol. 16, no. 3, pp. 1115-1125, 2019.

[6] M. Dursan and A. FautBoz, "The analysis of different techniques for speed control of permanent magnet synchronous motors," Tehnicki Vjesnik, vol. 22, no. 4, pp. 947-952, 2015.

[7] E. Ojionuka, et al., "A simplified sensorless speed control of permanent magnet synchronous motor using model reference adaptive system," Journal of Electrical Engineering, vol. 70, no. 6, pp. 473-479, 2019.

[8] B. Singh, et al., "DSP based implementation of direct torque control scheme for permanent magnet synchronous motor drive," IE(I) Journal-EL, vol. 88, pp. 35-44, 2007.

[9] S. Rizvi and A. Memon, "An extended observer-based robust nonlinear speed sensorless controller for a PMSM," International Journal of Control, vol. 92, no. 9, pp. 2123-2135, 2018.

\footnotetext{
A robust high-speed sliding mode control of permanent magnet synchronous ... (Ifeanyi Chinaeke-Ogbuka)
} 
[10] F. Poltschak, et al., "A dynamic nonlinear model for permanent magnet synchronous machines," 2008 IEEE International Symposium on Industrial Electronics, Cambridge, 2008, pp. 724-729.

[11] Y. Yan, et al., "Robust speed regulation for PMSM servo system with multiple sources of disturbances via an augmented disturbance observer," IEEE/ASME Transactions on Mechatronics, vol. 23, no. 2, pp. 769-780, 2018.

[12] A. Nguyen, et al., "Disturbance attenuation for surface-mounted PMSM drives using nonlinear disturbance observer-based sliding mode control," IEEE Access, vol. 8, pp. 86345-86356, 2020.

[13] P. Kakosimos and H. Abu-Rub, "Deadbeat predictive control for PMSM Drives With 3-L NPC inverter accounting for saturation effects," IEEE Journal of Emerging and Selected Topics in Power Electronics, vol. 6, no. 4, pp. 1671-1680, 2018.

[14] S. Diao, et al., "A differential algebraic estimator for sensorless permanent-magnet synchronous machine drive," IEEE Transactions on Energy Conversion, vol. 30, no. 1, pp. 82-89, 2015.

[15] S. Li and H. Gu, "Fuzzy adaptive internal model control schemes for PMSM speed-regulation system," IEEE Transactions on Industrial Informatics, vol. 8, no. 4, pp. 767-779, 2012.

[16] M. Morawiec, "The adaptive backstepping control of permanent magnet synchronous motor supplied by current source inverter," IEEE Transactions on Industrial Informatics, vol. 9, no. 2, pp. 1047-1055, 2013.

[17] W.J. Xu, "Permanent magnet synchronous motor with linear quadratic speed controller," Energy Procedia, vol 14, pp. 364-369, 2012.

[18] H. Erdogen and M. Ozdemir, "Neural Network Approach on Loss Minimization Control of PMSM with Core Resistance Estimation," Turkish Journal of Electrical Engineering \& Computer Sciences, vol. 25, pp. 1643-1656, 2017.

[19] S. Dandan, et al.,"Sliding mode controller for permanent magnet synchronous motors," Energy Procedia, vol. 105, pp. 2641-2646, 2017.

[20] L. Wegie, et al., "On Sliding Mode Control of Permanent Magnet Synchronous Motor," The 26th Chinese Control and Decision Conference (2014 CCDC), Changsha, 2014, pp. 4555-4559

[21] A. Karakaya and E. Katakas, "Performance analysis of pm synchronous motors using fuzzy logic and self tuning fuzzy pi speed controls," Arabian Journal for Science and Engineering, vol. 33, no. 1, pp. 153-178., 2008.

[22] C. Ogbuka et al., "A high performance hysteresis current control of permanent magnet synchronous motor drive," Turkish Journal of Electrical Engineering \& Computer Sciences, vol. 25, no. 1, pp. 1-14, 2017.

[23] K.C. Odo, et al, "A model-based PI controller tuning and design for field oriented current control of permanent magnet synchronous motor," IOSR Journal of Electrical and Electronics Engineering (IOSR-JEEE), vol. 14, no. 4, pp. 35-41, 2019.

[24] J.Q. Han, "Nonlinear state error feedback control law-NLSEF," Control and Decision, vol 10, pp. 177-183, 1995.

[25] A. Hosseyni, "An Improved sensorless sliding mode control/adaptive observer of a five-phase permanent magnet synchronous motor drive," The International Journal of Advanced Manufacturing Technology, vol. 93, pp. 1029-1039, 2017.

[26] Z. Zhou, "Robust sliding mode control of PMSM based on rapid nonlinear tracking differentiator and disturbance observer," Sensors, vol.18, no. 4, p.1031, 2018.

\section{BIOGRAPHIES OF AUTHORS}
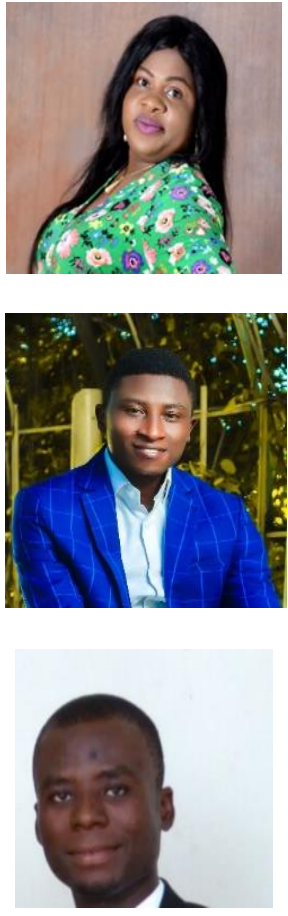

Engr. Ifeanyi Chinaeke-Ogbuka was born in Nsukka Nigeria on 14th September 1989. She obtained her Bachelors of Engineering (B.Eng) in Electronic Engineering and Masters of Engineering (M.Eng) also in Electronic Engineering Department of the University of Nigeria, Nsukka. She currently serves as a Lecturer II in the same Department. Her research interests are in Electronic, Communications, Control, and Instrumentation. She is a member of the Nigerian Institution of Electrical and Electronic Engineers (NIEEE). She has published in peer-reviewed journals and presented papers in refereed conferences.

Ajibo, Chinenye Augustine, is an academic staff of the Department of Electronic Engineering, University of Nigeria Nsuuka, Enugu-Nigeria. He obtained his B.Eng. and M.Eng. in Electronic Engineering and Telecommunication Engineering respectively from the same department. He is currently undergoing his Ph.D. studies at the Department of Systems Innovation, Graduate School of Engineering Science, Osaka University, Japan. He has over the years published research articles in reputable journals and conferences. His research interest includes Artificial Intelligence, Natural Language Processing, Human-Robot-Interaction, and Cognitive Science, Internet of Things (IoT), Cloud computing, Big Data, Wireless networks.

Odo Kenneth Chinonso graduated from the Department of Electrical Engineering University of Nigeria Nsukka with First Class Honours in 2017 and is currently a Graduate Assistant in the department. He is, at the moment, pursuing his Masters of Engineering (M.Eng) in the specialist area of of Power Electronics Devices and New Energy Systems at the Africa Centre of Excellence for Sustainable Power and Energy Development (ACE-SPED), University of Nigeria, Nsukka. 


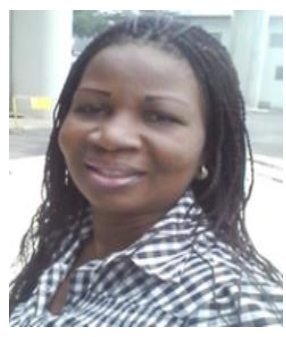

Uche Ogbuefi major in Electrical Power Systems. She obtained her Doctorate Degree (Ph.D) in Electrical Engineering from University of Nigeria, Nsukka in 2013. M.Tech in Electrical Engineering from Rivers State University, Nkpolu-Oroworukwu, Port Harcourt and a B.Eng. Degree from the Electrical/Electronic Engineering Department, University of Port Harcourt in 2009. She worked with many companies before she joined the academic world as a Lecture in the Department of Electrical Engineering, University of Nigeria, Nsukka. She is a corporate member of the Nigeria Society of Engineer (NSE), a COREN registered Engineer and also a member of Association of Professional Women in Engineering (APWEN). Member International Association of Engineers (IAENG). She has articles published in both local and international journals and conference proceedings. She has also authored and co-authored some book chapters. Her research interest include Electric Power Systems and Control; Optimization, Fault Analysis, Renewable Energy Resources, Renewable Energy Technology, and Integration.

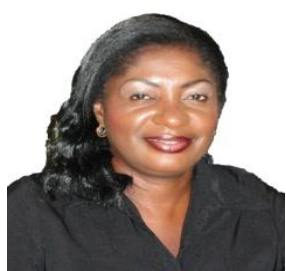

Mbunwe Muncho Josephine had her Bachelor of Engineering (B. Eng) in Electrical Engineering and Masters (M. Eng) in Electric Power Systems in 2000 and 2005 respectively. She is a lecturer in the department of Electrical Engineering, University of Nigeria, Nsukka. She is also a member of Nigeria Society of Engineers (NSE) since 12th July 2009 and joins the Council for the Regulation of Engineering in Nigeria (COREN) since 18th September 2014.Her research interests include embedded generation of renewable and non-renewable energy in Electric Power Systems. She had worked as site Engineer for Rural Electrification projects in some communities in Enugu State and Anambra State of Nigeria. She has published papers in some journals and in conference proceedings.

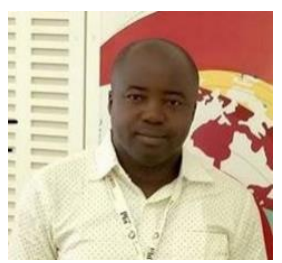

Engr. Dr. Cosmas OGBUKA holds the following degrees from the Department of Electrical Engineering, University of Nigeria Nsukka, where he has attained the rank of Senior Lecturer: B.Eng. (First Class Honors), M.Eng. (Distinction) and Doctor of Philosophy (Ph.D.) obtained in 2004, 2009, and 2014 respectively. His research interests include Electrical Machines, Drives and Power Electronics. He is an International Faculty Fellow of the Massachusetts Institute of Technology (MIT) USA and had also undertaken a postdoctoral research visit at the Chair of Electrical Drives and Actuators (EAA) Universitaet der Bundeswehr Muenchen Germany. He is currently the Director of the Computer Communications Centre of the University of Nigeria.

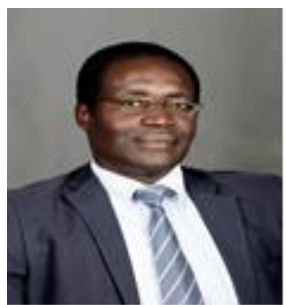

Emenike Ejiogu is a Professor of Power Electronics in the Department of Electrical Engineering, University of Nigeria Nsukka. He obtained his Doctor of Philosophy in Power Devices \& Systems at Shinshu University, Nagano-city, Japan in 1994 and has been a Research Professor at Mirai Research Labaratory, High Tech Research Centre, Ritsumeikan University, Kustatsu-shi, Shiga-ken, Japan since 2009. He was the Director-General/Chief Executive Officer (CEO), MicroSilitron Inc., Laboratory, Biwako Campus, Faculty of Science \& Engineering, Ritsumeikan University, Kusatsu-city, Japan from 2007 to 2009. He is the Principal Investigator of the Laboratory of Industrial Electronics, Power Devices and New Energy Systems, University of Nigeria Nsukka. He is also the Director/Centre Leader of the World Bank Africa Centre of Excellence for Sustainable Power and Energy Development (ACESPED), University of Nigeria, Nsukka. Prof. Ejiogu has over six (6) international patents/inventions in engineering to his credit and over 65 publications in peer reviewed international journals \& conferences 